\title{
An indirect method implementing effect of the wind on moored ship experimental tests
}

\author{
Lázaro Redondo, Rubén Méndez, Luis Pérez-Rojas
}

\begin{abstract}
Traditionally, moored ship tests with small-scale models only take into account the disturbance effect of waves. In this paper, the design and testing of a system also implementing the effect of wind in moored ships is analysed. The system is based on rotatory actuators acting on linear springs. This solution has a swift enough response to reproduce the fluctuating component of the wind. Three scenarios have been tested: waves, wind and combination of both. In order to assess the results, different sensors are connected to a computer for data acquisition, allowing the recording and subsequent analysis of the measured variables (forces in ropes, reactions in fenders and ship motions).
\end{abstract}

The results obtained from the experiments show a great impact when wind effect is considered. A superposition effect is observed when waves and wind act together on the ship, emphasizing therefore the importance of taking the wind into account in berthed vessel tests, achieving safer and more realistic results. 


\section{Introduction}

Small-scale model testing is a very useful tool, and in some occasions the only reliable tool, in order to predict the behaviour of real-scale phenomena (Xian-Ying et al., 2014; Hughes, 1993). It is clear this in not a modern technique and it is recorded that Leonardo da Vinci (1452-1519) carried out tests on three ship models having different fore and aft distribution of volumes (Tursini, 1953), but it is still very useful. In this paper, the particular case of berthed ships is addressed.

In the case of berthed ships, the main purpose of small-scale model testing is to estimate the range of tensions in the ropes, reactions in the fenders and amplitudes of the ship motions, leadings to representative measurements of a real-scale behaviour.

A berthed vessel is considered to be an oscillating system whose motions are restricted by mooring lines and fenders, and is therefore subjected to external excitations imposed by currents, tides, waves and wind (Gomez Pina and Iribarren Alonso, 1993).

Traditionally, moored ship tests with small-scale models only take into account the disturbance of waves and, in some cases, also tides. The interest in also reproducing the effects of wind as an additional disturbance has been increasing over the last few years (Fujiwara et al., 2006; Haddara and Guedes Soares, 1999). Nowadays however, there are experimental centres capable of performing moored ship tests including this effect (Table 1). Nevertheless, It must be pointed out that the use of wind fans in the case of offshore structure tests, dates back to at least 1990 .

Different ways to reproduce wind effect in moored ship tests have been found in the experimental centres consulted. They are listed in Table 1. Those can be divided in two groups: direct generation and indirect generation methods. The direct generation consists in applying an air current directly onto the model, normally by using a set of fans (Fig. 1). This is the natural way to represent the problem since wind effect in terms of forces and moments are easily solved.

The other method, indirect generation consists in applying the previously calculated resultant forces and moments on the model, such that they would represent the wind effect. These forces and moments can be implemented simply by using dead weights acting on the model through pulleys, with air impellers attached to the model, or with a set of force actuators acting on the model. The use of dead weights is justified when only constant forces and moments are expected to be reproduced. The indirect generation methods using actuators or "servo-winches" (a particular type of actuators that use rotatory servo-motors, pulleys and acting lines), seem to be more appropriate than the direct generation, when reproducing the wind fluctuation components, although those rely on an accurate aerodynamic characterisation of the ship model.

According to the documentation consulted, in offshore structures, fans are rarely used and servo-winches are preferred due to reasons of cost and repeatability. However in berthed vessels the use of fans is much more frequent nowadays. Actually, no papers or articles about the use of other methods on berthed vessels have been found (excluding dead weights).

Table 1, shows some of the experimental centres capable to generate waves and wind. The wind generation method is shown in the fourth and fifth columns, although it has not been found clarified whether these methods are applied in berthed vessel tests.

The aim of the present work is the design, testing and analysis of an indirect generation method that implements the effect of the wind on a moored ship. The system uses rotatory actuators acting on linear springs, controlled by a force control loop.

In order to assess the importance of the wind effect contribution when considering its fluctuation component, different combinations of external conditions were tested: waves only, wind only with different directions, and both waves and wind. The train of waves used in the experiments was identical.

Finally, for each testing case, tensions in the mooring lines, reactions from the fenders, and ship motions were measured. Different sensors connected to a computer through their signal conditioners were used, allowing for the recording and subsequent analysis of the measurements.

\section{Model experiment}

\subsection{Model, law, scale}

The non-distorted physical model was constructed according to a linear length scale of 1:150. The inertial and gravity forces were far more important to the model than other properties, such as surface tension and viscosity. Therefore, modelling was performed according to the Froude similarity law, without distortions of scale. This means that the scale factor between the prototype and the model is the same in the 3 space dimensions (Hughes, 1993; Chakrabarti, 1998; Blendermann, 1993).

The 3D model of the port was built using the wire technique (Gomez Pina and Iribarren Alonso, 1993), that the bathymetry was reproduced with steel wires fixed to vertical rods welded to lengths corresponding to the depth of each point in question. Subsequently, the bottom was filled with gravel, and finished with a $5 \mathrm{~cm}$ thick layer of mortar. Finally, the surface was smoothed to minimize friction (following pictures, Fig. 2).

Port facilities (piers, docks and basins) were reproduced with different materials and construction methods. The breakwaters were built using blocks and stones of calibrated weights and dimensions, and the docks were built with bricks and mortar.

The port used for this study was the one showed in Fig. 3. It corresponds to a Spaniard northern port which was built for agitation essays and ship mooring tests. The ship used in the experiments is shown moored at the top-left corner.

\subsection{Wave and wind characteristics}

The waves used in the tests were adjusted to the JONSWAP spectra (Hughes, 1993; Chakrabarti, 1998). The characteristics of these waves were: Direction N-050-W. Peak period: $P_{P}=1.21 \mathrm{~s}$ (model), $14.8 \mathrm{~s}$ (real scale). Significant height: $\mathrm{Hs}=3 \mathrm{~cm}$ (model), $4.57 \mathrm{~m}$ (real scale). These data were obtained from Ports of the 


\begin{tabular}{|c|c|c|c|}
\hline \multicolumn{3}{|c|}{ Nomenclature } & \multirow{3}{*}{$\begin{array}{l}\text { speed }\left(\mathrm{m}^{2} / \mathrm{s}\right) \text {. } \\
\text { Stern spring lines } \\
\text { Aft spring lines }\end{array}$} \\
\hline & & SPP & \\
\hline A & Projected lateral area of the ship & SPR & \\
\hline C & Gearbox ratio & $t$ & Time \\
\hline$C_{D}$ & Surface Drag Coefficient & $\mathrm{tf}$ & Transfer function \\
\hline CoG & Centre of gravity & ТРP & Stern breast lines \\
\hline$C_{x}, C_{y}$, & Aerodynamics coefficients & TPR & Aft breast lines \\
\hline$D 1, D 2$ & 3, D4 Fenders $1,2,3,4$ & $u$ & Input of the tf \\
\hline DOF & Degrees of freedom & $V_{v}$ & Average wind velocity at the reference height of $10 \mathrm{~m}$ \\
\hline$f$ & Frequency & & $(\mathrm{m} / \mathrm{s})$ \\
\hline $\mathrm{Fl}$ & Longitudinal force & $V_{W R}$ & Modulus of wind velocity \\
\hline Ft1 & Transverse force 1 & $x 1$ & Distance from CoG to Ft1 application point \\
\hline Ft2 & Transverse force 2 & $x 2$ & Distance from CoG to Ft2 application point \\
\hline$F_{X}$ & Force in the direction of the $X$ axis (longitudinal axis) & $\bar{f}$ & Non-dimensional frequency \\
\hline$F_{Y}$ & Force in the direction of the $Y$ axis (transverse axis) & & \\
\hline Hs & Significant height & Units & \\
\hline$K$ & Spring constant & & \\
\hline$L$ & Length between perpendiculars & $\mathrm{cm}$ & Centimetre \\
\hline LPP & Head lines & $\mathrm{m}$ & Metre \\
\hline LPR & Aft lines & $\mathrm{m} / \mathrm{s}$ & Metre per second \\
\hline$M_{Z}$ & Yawing moment & $\mathrm{N}$ & Newton \\
\hline PID & Proportional, integer and derivative & $\mathrm{s}$ & Second \\
\hline Pр & Peak period & $\mathrm{rpm}$ & Revolution per minute \\
\hline PP & Perpendicular & $\mathrm{t}$ & Tonne \\
\hline $\mathrm{pt}$ & Point & $\mathrm{V}$ & Volt \\
\hline$r$ & Radius & W & Watt \\
\hline & Air density $\left(1.225 \mathrm{Kg} / \mathrm{m}^{3}\right)$ & & \\
\hline $\operatorname{Svf}(\mathrm{f})$ & Power spectral density corresponding to the wind & & \\
\hline
\end{tabular}

State (www.puertos.es) and corresponds to the average sea conditions at the port tested. For the wave train generation, a hydraulic piston-type wave board was used (Hughes, 1993; Natarajan and Ganapathy, 1995).
The wind characteristics were obtained from the Spanish standard on maritime works (ROM 0.4-95, 1995). According to the latter, the average speed on the Spanish coast is the range of: $10 \mathrm{~m} / \mathrm{s}$ in the Valencian coast and $15 \mathrm{~m} / \mathrm{s}$ in the Cantabrian coast.

Table 1

Some experimental centres with waves and wind simulation.

\begin{tabular}{|c|c|c|c|c|c|}
\hline Country & Centre & Facility & Fans $^{\mathrm{a}}$ & Other methods & Source $^{\mathrm{b}}$ \\
\hline Australia & Australian Maritime College & Model Test Basin & $2 \mathrm{x}(10)$ & & 1 \\
\hline Brazil & LabOceano & Ocean Basin & $\mathrm{X}$ & & 22 \\
\hline Canada & NRCI for Ocean Technology & Offshore engineering basin/Towing Tank & $12 / 8$ & & 4,5 \\
\hline China & $\begin{array}{l}\text { Ship Hydrodynamics Lab Shanghai Jiao Tong } \\
\text { University }\end{array}$ & Ocean engineering basin & $\mathrm{X}$ & $\begin{array}{l}\text { Wind tunnel circulating wáter } \\
\text { channel }^{\mathrm{C}}\end{array}$ & 7 \\
\hline Denmark & DHI water and environment & Shallow Water Basin & $\mathrm{X}$ & Dead weights & 9 \\
\hline Italy & INSEAN & Towing Tank & $2 x(6)$ & & 13 \\
\hline Japan & TETRA Co. Ltd. & First large-scale wave basin & & Actuator & 20 \\
\hline Japan & National Maritime Research Institute & Actual Sea Model Basin/Ocean Engineering Tank & $\mathrm{X}$ & $\begin{array}{l}\text { Pulsating Wind Tunnel with Water } \\
\text { Tank }\end{array}$ & 14 \\
\hline Korea & MOERI (KRISO) & Ocean Engineering Basin & $\mathrm{X}$ & & 6 \\
\hline Netherland & DELTARES & Shallow Water Basin & $\mathrm{X}$ & Dead weights & 2,12 \\
\hline Netherland & MARIN & $\begin{array}{l}\text { Offshore/Seakeeping \& Manoeuvring/Shallow } \\
\text { water basins }\end{array}$ & $\mathrm{X}$ & springs & 21,19 \\
\hline Norway & SINTEF (Marintek) & Ocean Basin & $\mathrm{X}$ & & 15 \\
\hline Russia & Krilov Shipbuilding Research Institute & Sea keeping basin & $\mathrm{X}$ & & 16 \\
\hline Spain & IH Cantabria & Coastal and Ocean Basin & 9 & & 10 \\
\hline Spain & CEHIPAR & Ship Dynamics Laboratory & & Impeller on model \& Weights & 11 \\
\hline Spain & CEDEX & Coastal and Ocean Basin & 1 & Servo winch \& Dead weights & CEDEX \\
\hline Spain & Canal de Experiencias hidrodinámicas de la UPM & Towing Tank & & Impeller on model & 23 \\
\hline USA & Texas A\&M University & OTRC Wave Basin & 16 & Servo winch \& Dead weights & 17,18 \\
\hline USA & University of Maine & W2 Wind-Wave Basin & & Wind Tunnel Open-jet & 24 \\
\hline USA & $\begin{array}{l}\text { Scripps institution of oceanography UC San } \\
\text { Diego }\end{array}$ & Wind wave channel & & Open circuit wind tunnel & 25 \\
\hline
\end{tabular}

In our case inside the wind tunnel is a channel with waves.

a " $\mathrm{X}$ " means an undetermined number of fans. A number, is the number of fans.

$\mathrm{b}$ in section References, Table 1.

${ }^{c}$ A wind tunnel is a tool used in aerodynamic research to study the effects of air moving past solid objects. A wind tunnel consists of a tubular passage with the object under test mounted in the middle. Air is made to move past the object by a powerful fan system or other means. 


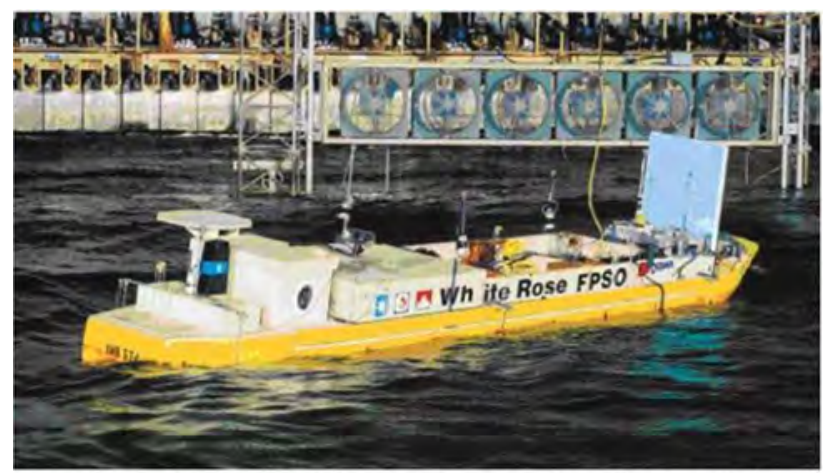

Oceanic Consulting Corporation (Canada)

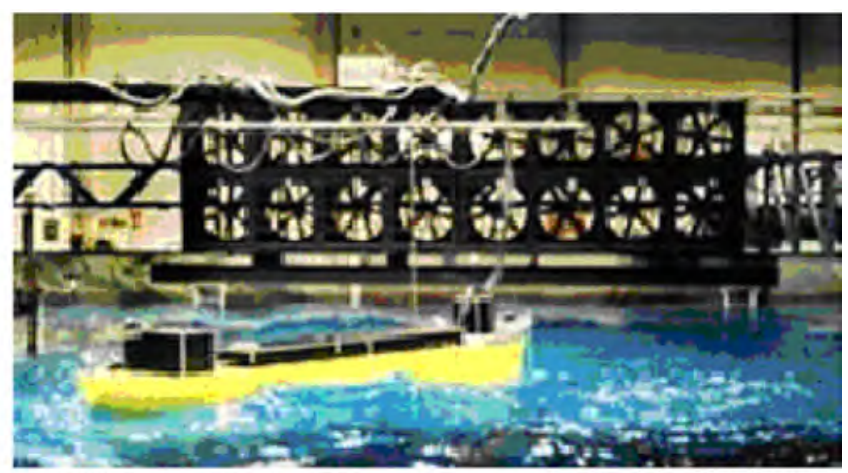

Offshore Technology Research Center (USA)

Fig. 1. Examples of facilities using fans.
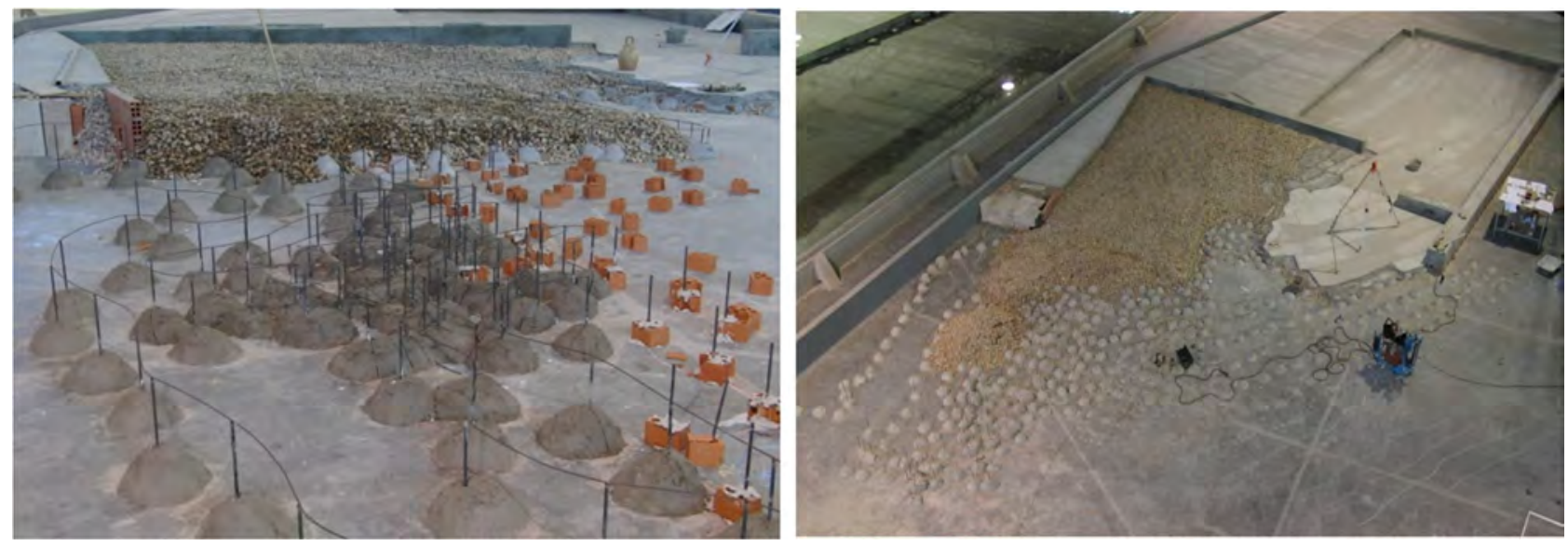

Fig. 2. Pictures about the physical model building.

For this study the highest value of $15 \mathrm{~m} / \mathrm{s}$ at a $10 \mathrm{~m}$ height was taken.

\subsection{Ship model}

The vessel chosen for the experiment was a cruise ship, which was berthed at the top left pier of the model port showed in Fig. 3.

The construction of the tested vessel, as well as the adjustment of its dynamic characteristics and parameters (metacentric height, natural inertia period of roll, heave and pitch) were performed according to the Froude similarity law.

Table 2 shows the main characteristics of the real-scale cruise ship, and Fig. 3 shows the arrangement of the mooring lines and fenders.

The centre of pressure, the point where the total sum of a pressure field acts, resulting in an equivalent force acting through

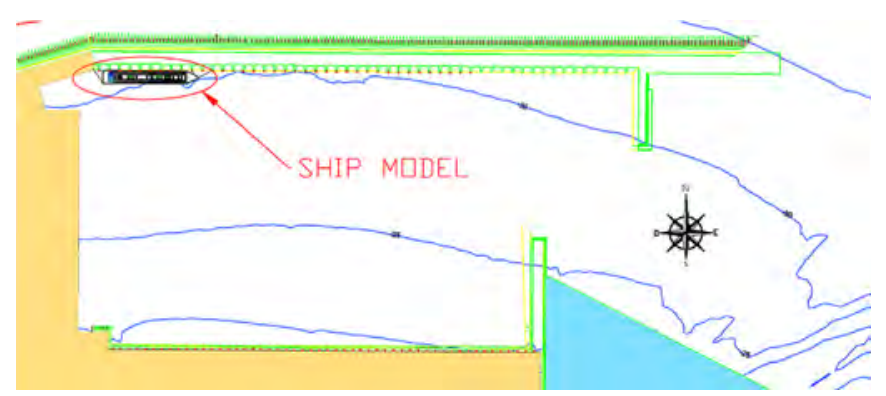

Fig. 3. Overall layout of the port model. that point, is located at $16.7 \mathrm{~m}$ high above the waterline. The application points of the wind force implementation were considered to be at this height. It is assumed that the centre of pressure presents small variations as the vessel moves, although those were not considered relevant.

The ship's centre of gravity is located $5.31 \mathrm{~m}$ aft from the mean frame.

The prototype mooring configuration uses fourteen lines, which are distributed as follows, 3 head lines, 4 breast lines ( 2 bow and 2 stern), 4 spring lines ( 2 bow and 2 stern) and 3 stern lines. The rope characteristics were: diameter $80 \mathrm{~mm}$ and polypropylene. The maximum workload of these lines is $37 \mathrm{t}$. The maximum fenders workload is $232.2 \mathrm{t}$.

\subsection{Test devices}

In order to simplify the installation, the fourteen lines of the real mooring configuration were reproduced in the model by using only 6 , one per each type of line. In addition, four fenders were used in the model (Fig. 4).

The characteristics of the mooring lines and fenders were modelled based on the elastic properties of steel rods and plates, respectively. The elongation feature of each steel rod and plate was adjusted in order to accurately simulate the behaviour of the real mooring lines and fenders. Since only one line was used for each type of mooring, the steel rod used for each case reproduces the overall effect of the total number of lines. Every steel rod and plate has a built-in strain gauge registering tensions and reactions respectively. 
Table 2

Main characteristics of the ship.

\begin{tabular}{|c|c|c|c|c|c|c|}
\hline Scale & Length (m) & Length $\mathrm{PP}(\mathrm{m})$ & $\operatorname{Beam}(\mathrm{m})$ & Depth (m) & Draught (m) & Displacement $(\mathrm{t})$ \\
\hline 150 & 279.0 & 240.4 & 36.0 & 43.0 & 8.6 & $50,566.0$ \\
\hline
\end{tabular}

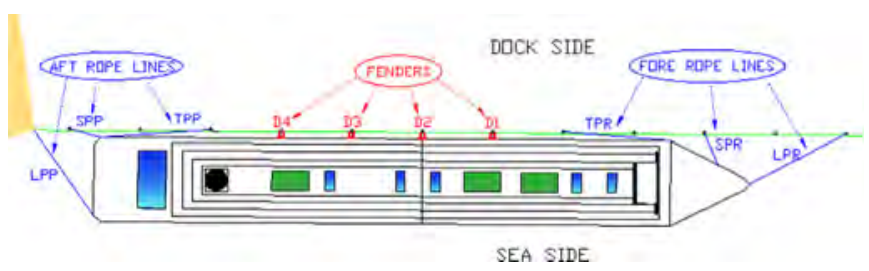

Fig. 4. Arrangement of mooring lines and fenders.

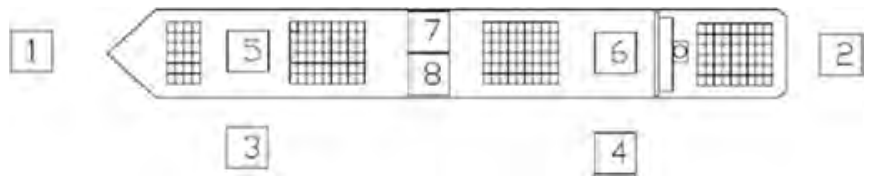

Fig. 5. Lasers' layout on the ship model.

Ships motions at berth were recorded using four pairs of lasers which directed the beams to specific points on the deck and the side of the ship. From these data, we obtained values of the translations (surge, sway and heave), and rotations of the ship (yaw, pitch and roll) with the following expressions according to the lasers' layout shown in Fig. 5. The results are already turned into real-scale units. $L x$ refers to the output of the laser $x$.

$$
\begin{aligned}
& \text { Surge }=\frac{L 1-L 2}{2}(\mathrm{~m}) \text { Roll }=\tan ^{-1} \frac{L 7-L 8}{\operatorname{Dist}(7-8)}(\text { deg. }) \\
& \text { Sway }=\frac{L 3+L 4}{2}(\mathrm{~m}) \text { Pitch }=\tan ^{-1} \frac{L 6-L 5}{\operatorname{Dist}(5-6)}(\text { deg. }) \\
& \text { Heave }=-\frac{L 5+L 6}{2}(\mathrm{~m}) \text { Yaw }=\tan ^{-1} \frac{L 4-L 3}{\operatorname{Dist}(3-4)} \text { (deg.) }
\end{aligned}
$$

The measurement equipment also includes a capacitive probe sensor which measures the wave height and period outside the harbour.

Every sensor was connected to a single computer for data acquisition through their respective signal conditioners (i.e. amplifiers and A/D converters), allowing the recording and subsequent treatment of the time series of the measured variables.

\section{Wind}

\subsection{Wind characterization}

In order to define the wind characteristics, both the speed at a specific height relative to the surface and the wind fluctuation must be taken into account. At a certain point and at a certain wind state (period of time, approximately between 1 and $3 \mathrm{~h}$, in which the mean speed wind does not change significantly), the wind speed can be considered as a composition of a constant value and a fluctuation component with zero mean value and Gaussian distribution (ROM 0.4-95, 1995; Blendermann, 1993). The fluctuation component to the wind speed (also called gust effect) can be characterized by the power spectral density. There are different theoretical formulations which try to represent the wind spectra corresponding to the fluctuation of the wind speed. Some of them are exposed by Bęc (2010) and Zaheer and Islam (2012). Those are shown in Fig. 6.

In the present study, the theoretical Spectrum of Davenport and Harris recommended in ROM 0.4-95 (1995) has been chosen. Its mathematical expression is:

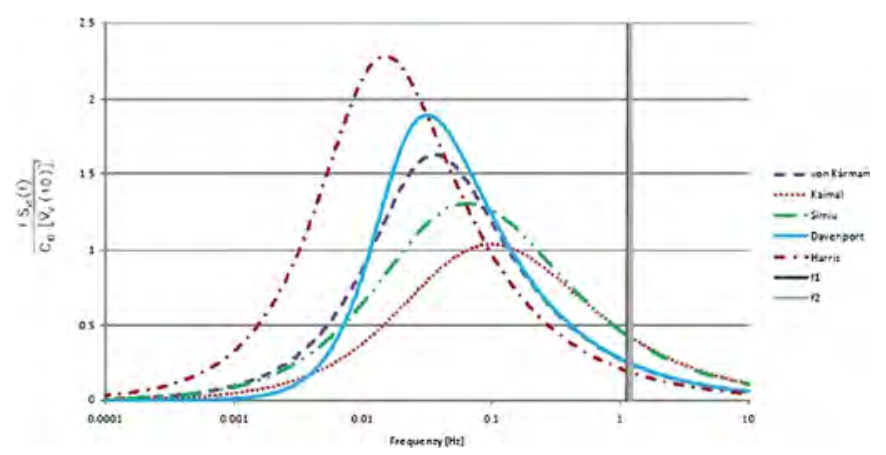

Fig. 6. Comparison of wind spectra (Bęc, 2010).

$\frac{f \cdot S_{v f}(f)}{C_{D}\left[V_{V}(10)\right]^{2}}=\frac{4 \cdot \bar{f}}{\left(2+\bar{f}^{2}\right)^{5 / 6}}$

where $\bar{f}$ non-dimensional frequency given by: $\bar{f}=\frac{1800 \cdot f}{V_{v}(10)}$

Svf $(f)$ : Spectral density function corresponding to the speed fluctuation wind power $\left(\mathrm{m}^{2} / \mathrm{s}\right)$.

$f: \quad$ Frequency $\left(\mathrm{Hz}\right.$ ó $\left.\mathrm{s}^{-1}\right)$.

$C_{D}$ : $\quad$ Surface Drag Coefficient (nondimensional).

$V_{v}(10)$ : Average wind velocity at the reference height of $10 \mathrm{~m}$ $(\mathrm{m} / \mathrm{s})$.

This spectrum is shown in Fig. 7.

Finally, by means of the Fourier Transform, the time series of the wind speed with the statistical characteristics of this spectrum were obtained.

The fluctuation component of the wind is considered very important in floating and moored structures, since their natural periods are close to the frequencies with significant amount of energy (ROM 0.4-95, 1995; Chakrabarti, 1998). A comparison between the Davenport and Harris spectrum and typical natural frequencies of some ships is shown in Fig. 8 (ROM 0.4-95-3). Note that the horizontal axis has already been turned into frequency $(\mathrm{Hz})$ considering $V_{v}(10)=15 \mathrm{~m} / \mathrm{s}$.

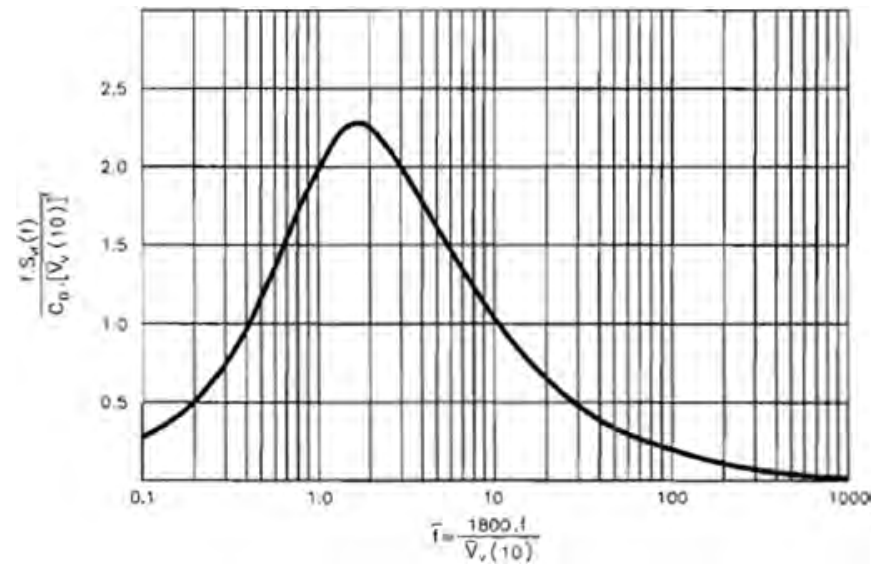

Fig. 7. Davenport and Harris spectrum. 


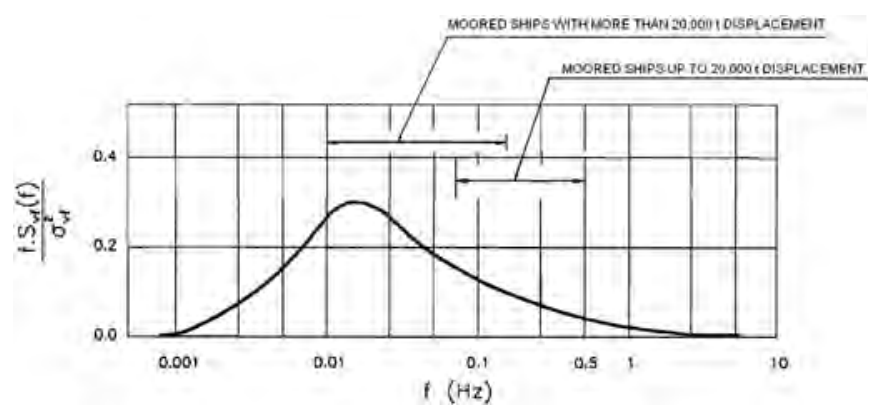

Fig. 8. Davenport and Harris wind spectrum vs some ship natural frequencies.

\subsection{Calculation of stresses on the ship}

The wind effect on a moored ship depends on the wind speed value and the angle of attack. This effect can be translated into a force and moment applied on the ship's centre of gravity (CoP). By reproducing these resulting force and moment on the ship model, it is possible to indirectly reproduce the wind effect.

The wind drag force is generally calculated with the following expression:

$F_{\text {WIND }}=1 / 2 \rho A\left|V_{W R}\right| V_{W R} C_{S}$

where:

- $\rho$ : Air density

- A: Projected area of the structure exposed to wind

- $V_{W R}$ : Wind velocity

- $C_{S}$ : Aerodynamic shape coefficient

Since the wind velocity direction is mainly horizontal, the most important acting forces and moments are those contained on the $X Y$ plane of the ship (Blendermann, 1993). See Fig. 9.

Their components referred to the ship's CoP can be obtained with the following expression:

$\left(\begin{array}{c}F_{X} \\ F_{Y} \\ M_{Z}\end{array}\right)=\frac{1}{2} \cdot \rho \cdot A \cdot V_{W R}^{2} \cdot\left(\begin{array}{c}C_{X} \\ C_{Y} \\ L \cdot C_{N}\end{array}\right)$

where

- $F_{X}$ : Force in the direction of the axis $X$ (longitudinal axis).

- $F_{Y}$ : Force in the direction of the axis $Y$ (transverse axis).

- $M_{Z}$ : Yawing moment.

- A: Projected lateral area of the ship.

- $L$ : Length between perpendiculars.

- $V_{W R}$ : Modulus of wind velocity.

- $\rho$ : Air density.

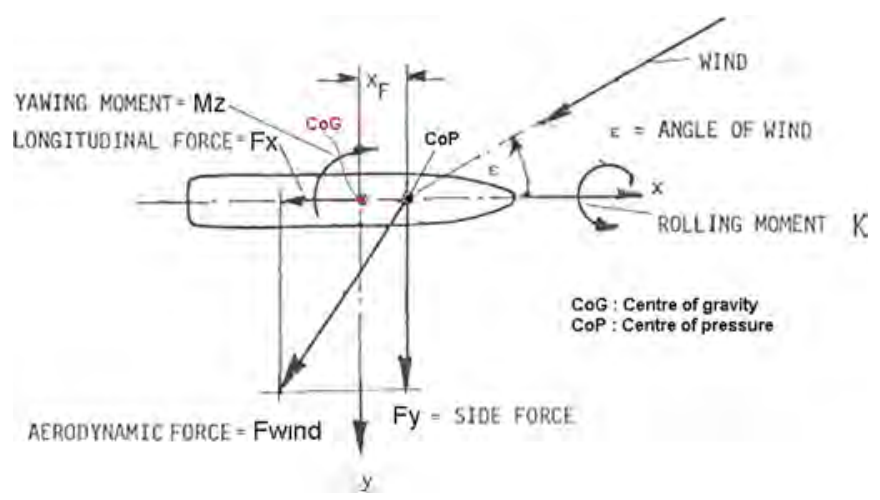

Fig. 9. Wind forces and moments.
- $C_{x}, C_{y}, C_{N}$ : Aerodynamics coefficients relative to the angle between the wind and the ship $\theta_{W R}$, corresponding to the longitudinal force, transverse force and moment in the ship's horizontal plane ( $X Y$ plane), respectively.

The aerodynamic coefficients can be deduced by means of numerical methods (Haddara and Guedes Soares, 1999) or also obtained experimentally in wind tunnels. Fig. 10 shows the value of the coefficients of the cruise ship used in the tests, for every angle. They were obtained from the database of the "Ship Manoeuvring Simulation System" of the Centre for Ports and Coasts Studies. These data are very similar to those presented by Fujiwara et al. (2006).

\subsection{Reproduction of stresses in the model}

After determining the resultant forces and yawing moment, by means of the rigid body properties, those are turned into three forces, two of them acting transversely and one more acting longitudinally. These three forces will finally act on the scale model of the ship, in the way that is shown in Fig. 11.

According to Newton's laws the three resultant forces on the ship model can be calculated as follows:

$\mathrm{F} 1=\mathrm{Fx}$

$\mathrm{Ft} 1=\mathrm{Fy}-\mathrm{Ft} 2$

$\mathrm{Ft} 2=\frac{\mathrm{Fy} \cdot \mathrm{x} 1-\mathrm{Mz}}{\mathrm{x} 1+\mathrm{x} 2}$

where:

- Fl: Longitudinal force.

- Ft1: Transverse force 1.

- Ft2: Transverse force 2 .

- $x$ 1: Distance from CoG to Ft1 application pt.

- $x$ 2: Distance from CoG to Ft2 application pt.

A software, which was specifically designed for this application, takes into account all the formulation exposed above, and generates automatically time series of these forces, Fl, Ft1 and Ft2.The inputs for this software are the wind velocity and direction, type of ship, orientation angle and scale of the model. Fig. 12 shows an example of the time series obtained from this software for our ship model with $15 \mathrm{~m} / \mathrm{s}$ wind and $150^{\circ}$ orientation angle.

Experimentally, it has been found that for every wind angle, the force acting in the longitudinal direction Fl had such a small average value that the influence of this force can be considered negligible compared to the overall effect of the wind (see the example of Fig. 12). Therefore, we decided to only reproduce the two transverse forces, namely Ft1 and Ft2.

\section{System used to reproduce the wind}

\subsection{System overview}

As mentioned in Section 1, the chosen system that reproduces the wind can be classified within the indirect generation, using force actuators to apply the forces and moments on the model by means of linear springs moved by rotatory motors.

The system consists of a closed-circuit structure which simultaneously applies a pair of forces on two opposite sides of the ship model. The difference between the pair of forces generates a resultant force applied on the vessel. The layout of the system is shown in the following figure.

In order to explain how the system works, let us begin with a zero resultant force situation, where the two forces $F 1$ and $F 2$ are 


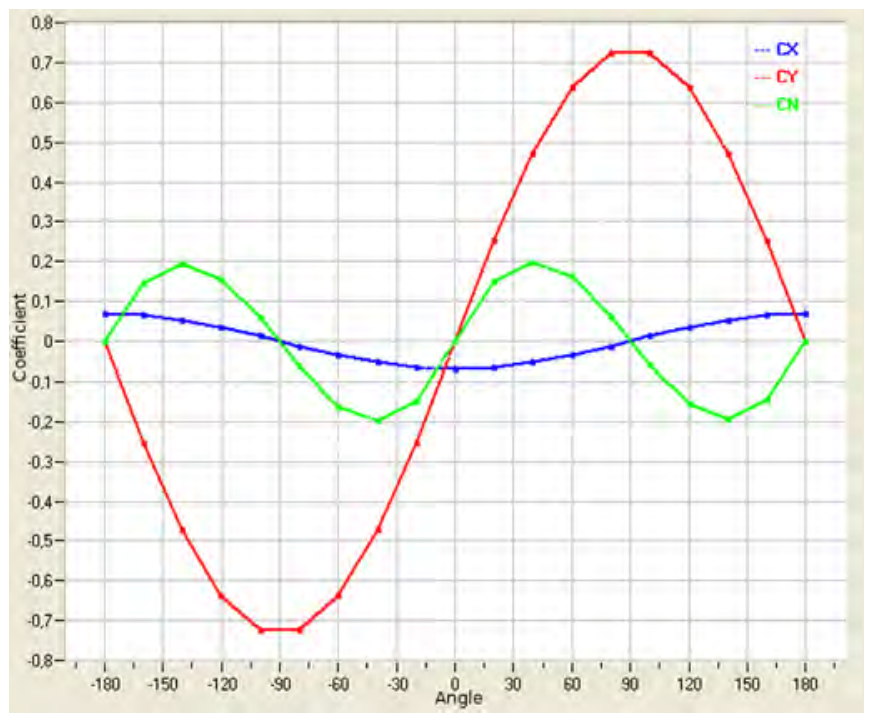

Fig. 10. Cruise ship wind coefficients.

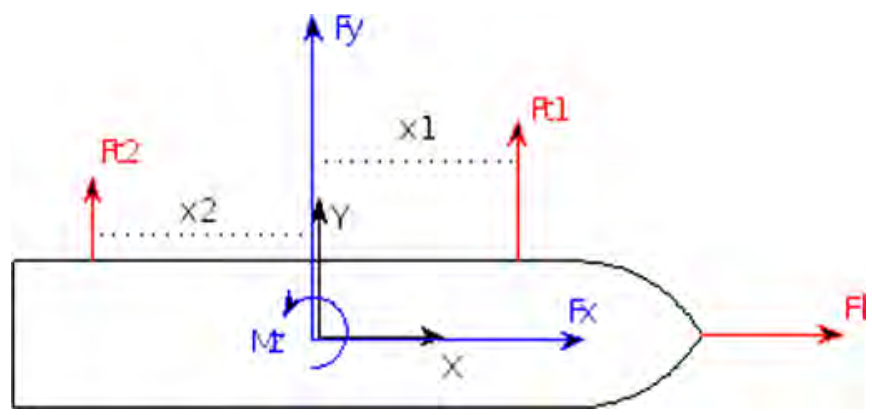

Fig. 11. Distribution of forces in the model.

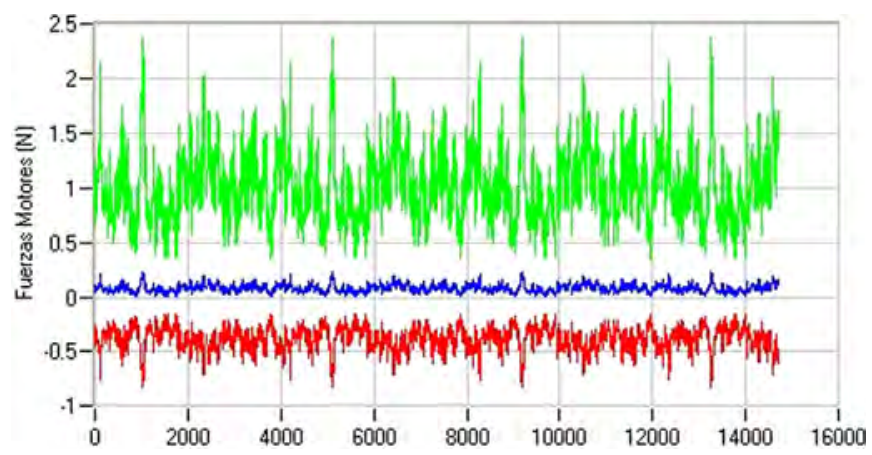

Fig. 12. Forces on cruise-ship model in Nw. Legend: Blue-Fl, Red-Ft1, Green-Ft2. (For interpretation of the references to colour in this figure legend, the reader is referred to the web version of this article.)

equal. When the motor rotates the driving pulley a certain angle, for instance clockwise according to Fig. 13, the spring 2 is lengthened and the force $F 2$ increases. By contrast, the spring 1 is shortened the same length and the force $F 1$ decreases. The effect is a resultant force acting from right to left, on the figure.

The whole system initially consists in using this configuration along three action lines in order to implement the forces Fl, Ft1 and Ft2 according to the layout shown in Fig 11. As mentioned in the previous section, the longitudinal force is much smaller than any of the transversal ones, Fl was therefore not taken into consideration. Hence, the final layout only uses this configuration

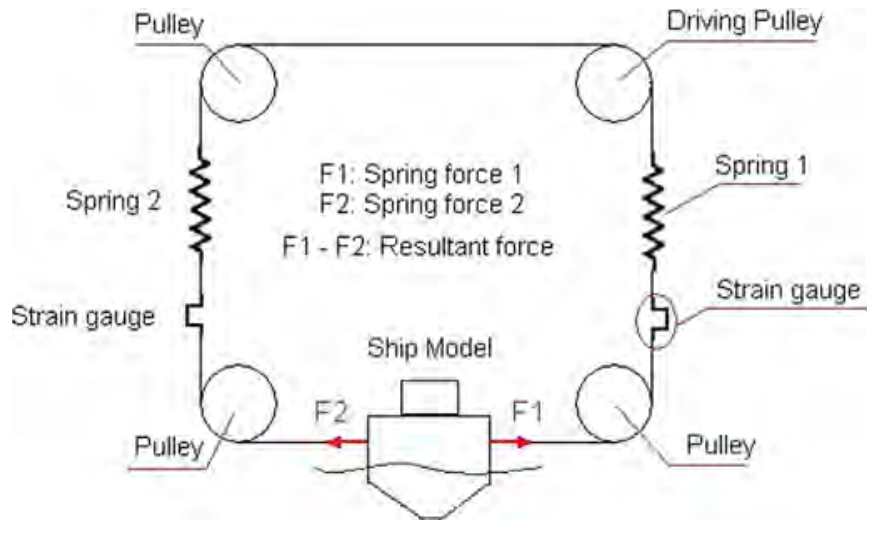

Fig. 13. Representation of the used configuration.

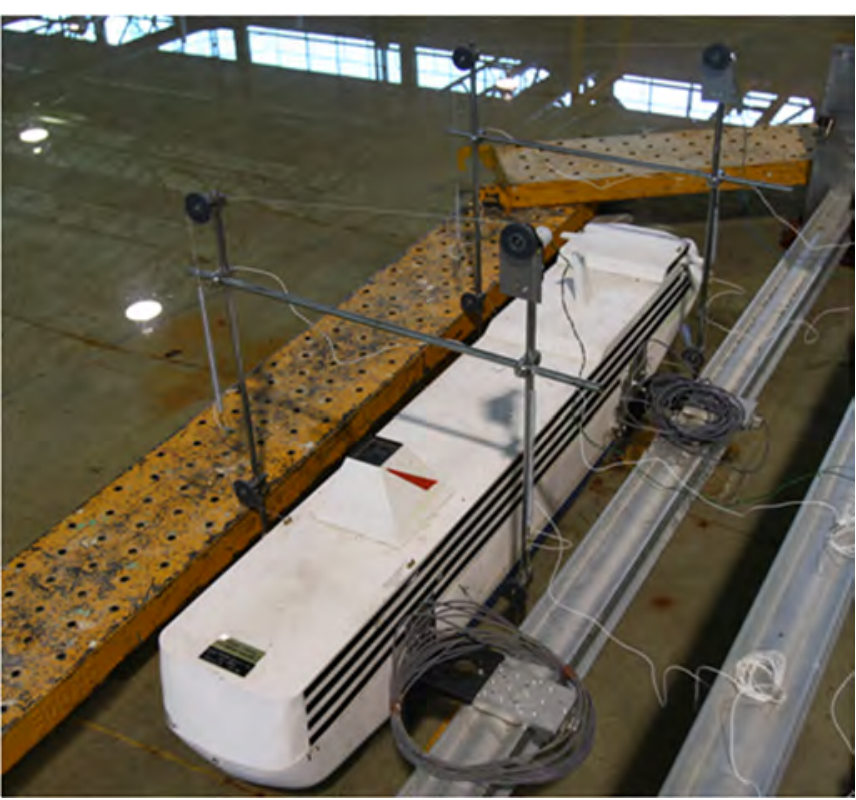

Fig. 14. Photo of the whole system.

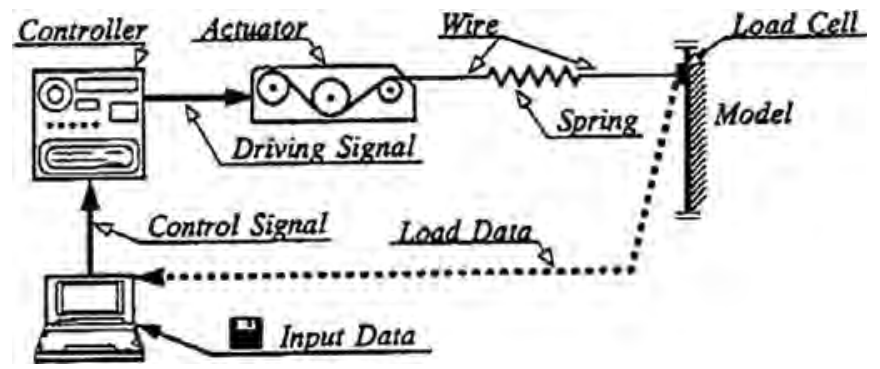

Fig. 15. Feedback control scheme.

twice, at two different points along the longitudinal direction of the vessel, reproducing Ft1 and Ft2 (see Fig. 14).

It must be noted that although quite short horizontal lengths between the pulleys and the vessel can be seen in both Figs. 13 and 14 , it is always more beneficial to separate the pulleys from the vessel as long as the test conditions allow it. This minimizes the geometric distortions in the direction of the applied force due to large amplitude ship motions. 


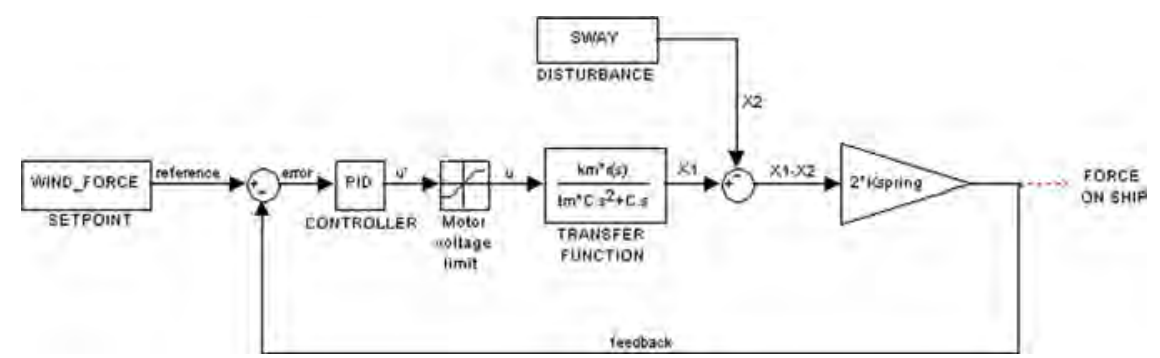

Fig. 16. Closed-loop control representation of wind implementation system. Performed with Simulink.
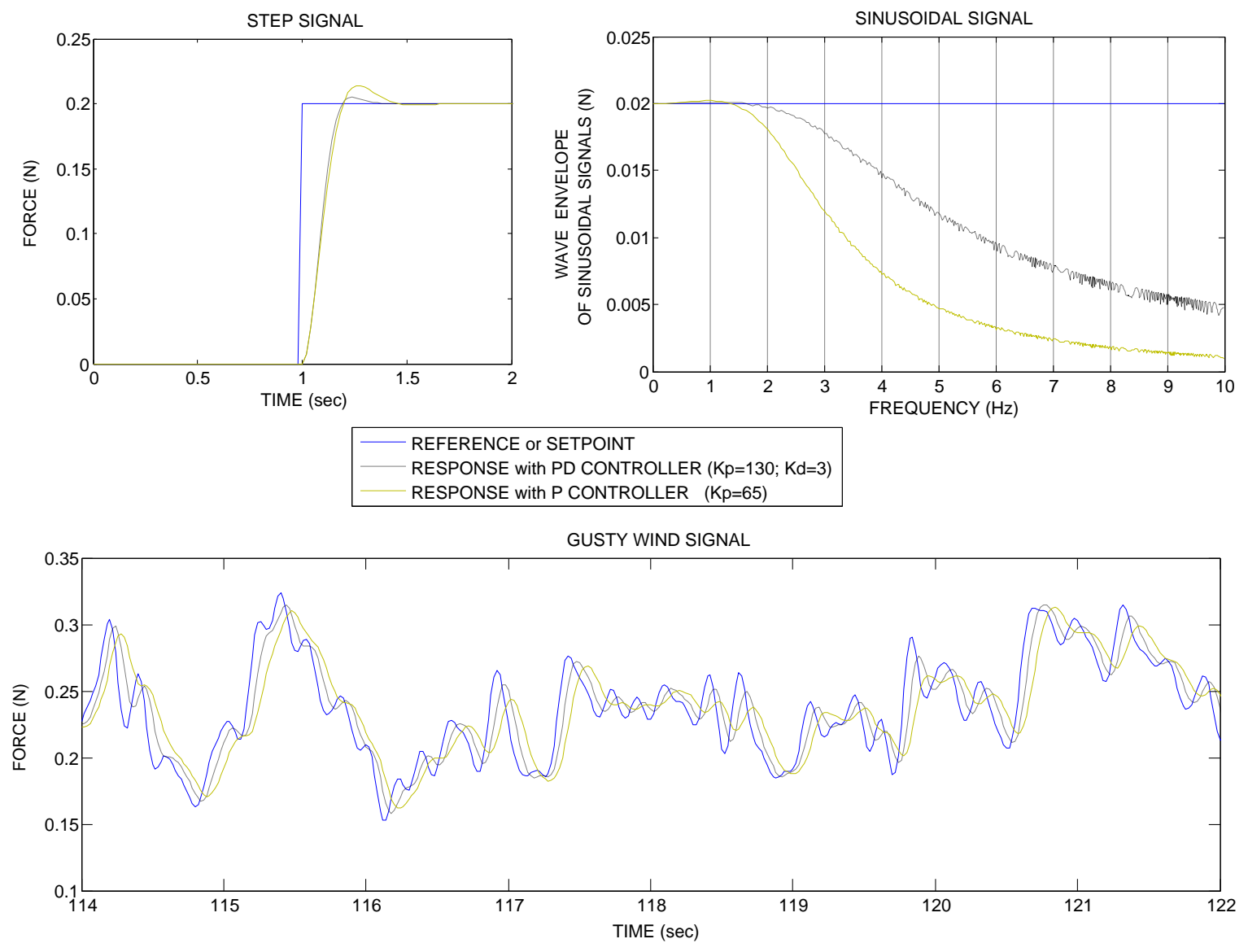

Fig. 17. Comparison P controller vs PD controller.

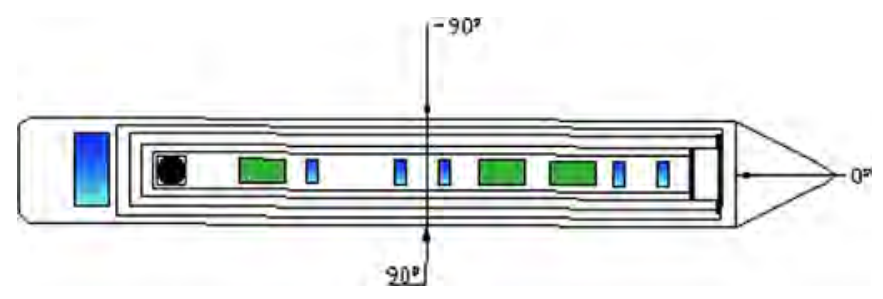

Fig. 18. Reference of wind direction angles.

\subsection{System components}

The main components of the system are electric motor, a gear box, 1 driving pulley, 3 driven pulleys, 2 springs and 2 strain gauges.

\subsubsection{Motor and gearbox}

The main characteristics of the selected motor were:

$\begin{array}{llll}\text { Voltage supply } & 12 \mathrm{~V} \mathrm{DC} & \text { Torque } & 0.73 \mathrm{~N}^{*} \mathrm{~cm} \\ \text { Power } & 3.8 \mathrm{~W} & \text { Nominal speed } & 5900 \mathrm{rpm}\end{array}$

To adjust the high rpm value of the motor to the action of the spring and pulley system, a gear box was used. That is, in order to adapt the system to different severity conditions and directions of the wind to implement, the following gear ratios were used:

15: 1 40: 1 80: 1 120: 1 .

\subsubsection{Springs}

The choice of the springs acting on the system was done according to the range of forces calculated for each pair of direction and severity condition. A suitable spring is one such that, for the whole range of applied forces, it deforms moderately within its linear range.

Thus, a deformation range of $4 \mathrm{~cm}$ and with a maximum scaled wind force value of $0.4 \mathrm{~N}$ (obtained with the help of the wind time series generation), the springs should have a maximum spring 


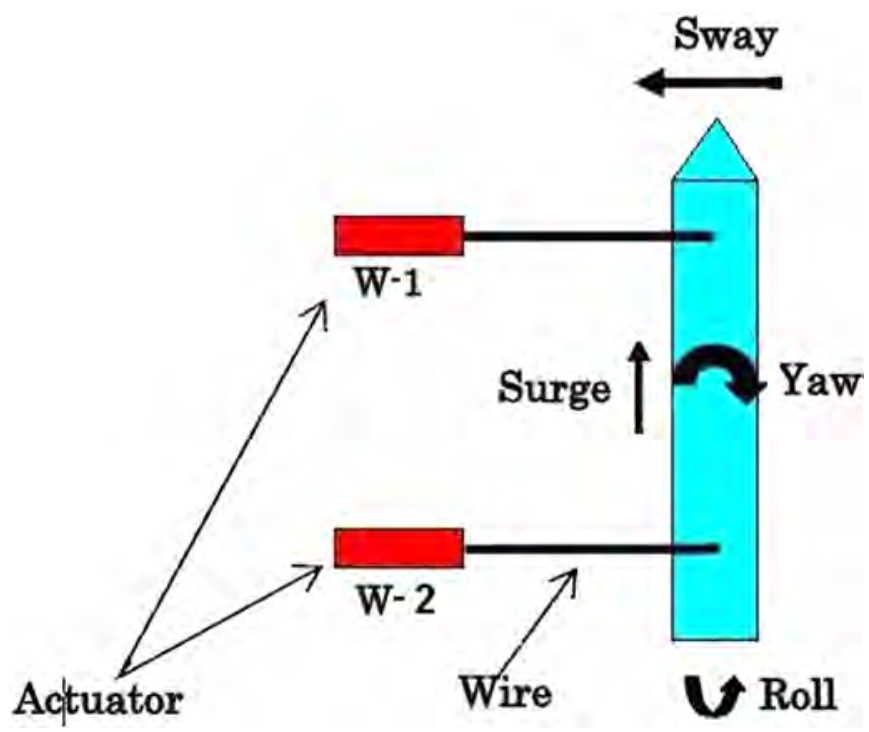

Fig. 19. Ship motions finally analysed, and actuators' layout.

constant equal to:

$K=0.4 \mathrm{~N} / 0.04 \mathrm{~m}=10 \mathrm{~N} / \mathrm{m}$.

Similarly for gear boxes, several types of spring constants, which would cover a wide range of forces for different wind directions, were used.

\subsubsection{Strain gauges}

The strain gauges are the elements which measure the force applied on each side of the closed-loop, and therefore the force acting on each side of the vessel. As was previously explained, the total force acting on the ship is the difference between both these forces.

The two strain gauge signals are amplified and filtered through a conditioner unit before they can be subtracted.

\subsubsection{PID}

The PID controller, is the element that receives a set signal, which for this case corresponds to the theoretical wind force, and compares it with the real measurement coming from the strain gauges. Then the PID calculates the error between them and generates a control action for the motor in order to minimize this error. This control strategy is called feedback control or closedloop control (see Fig. 15).

In general, PIDs have three adjustable parameters, also called "gains": proportional, integral and derivative. In order to obtain the optimal adjustment of these three gains, some theoretical

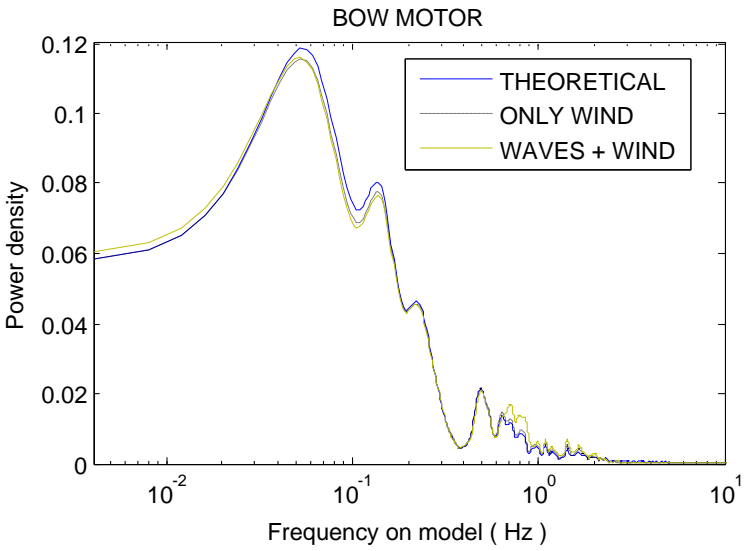

methods exist, based on the transfer function of the system (Chen, 1993). In the following paragraphs, a brief explanation on how to obtain this theoretical adjustment will be given.

Firstly, we obtain the transfer function (tf), of the relevant components of the wind implementation system (see Fig. 13). By assuming that both springs have the same constant, and taking a frequently used model for the DC motor (Chen, 1993), the resulting function can be seen below.

$x 1(S)=\frac{K m \cdot r}{S(t m \cdot C \cdot S)+C} \cdot u(S)$

where $u$ (input of the tf) is the motor voltage and $x 1$ (output of the tf) is the linear displacement at the driving pulley periphery. As can be seem from the system represented in Fig. 13, the displacement $x 1$ matches with the upper-end part of the spring to which the pulley is connected. This term, $x 1$, must be subtracted to the displacement of the lower-end part of the spring, $x 2$, in order to obtain the overall force on the ship. Since it can be assumed that the displacement $x 2$ is equal to the sway of the ship, the control system can be schematically represented as shown in Fig. 16.

With the help of the Matlab toolbox, Simulink, several simulations of the control system were tested. The transfer function parameters being used for these simulations were:

- Km: 50 Gain constant (rad/V s). (Ratio: steady state motor speed/voltage supply. $5800 \mathrm{rpm} / 12 \mathrm{~V}$ according to motor specs).

- tm: 0.05 Time constant (s) (Reaction time for the motor to reach the $66 \%$ of its final value. This value was chosen, after several simulations with Simulink, to be approximately equivalent to the physical system response, considering the effect of the existing inertias: pulleys, spring mass, motor).

- $r: 0.0235$ Pulley radius (m).

- C: 80 Gear box ratio.

- Kspring: 6.25 Rigidity constant of the springs ( $\mathrm{gr} / \mathrm{cm})$.

- \pm 12 Motor voltage limit (V).

After trying different combinations of the PID gains $\left(K_{P}, K_{I}, K_{D}\right)$, two optimal settings have been reached, depending on whether the controller used is a P controller or a PD controller. It was found that the integral gain $K_{I}$ does not improve the system response. The optimal adjustments found were:

- P controller: $K_{P}=65$.

- PD controller: $K_{P}=130, K_{D}=3$.

Then, a comparison of the system response using both optimal adjustments, with different excitation signals, was made. The results show a slightly better response in the case of the PD

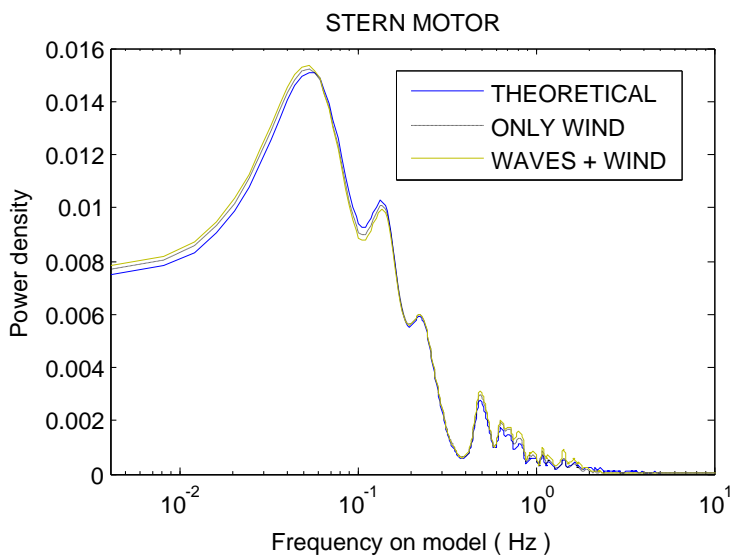

Fig. 20. Spectra of bow and stern wind signal following ( $30^{\circ}$ wind). 

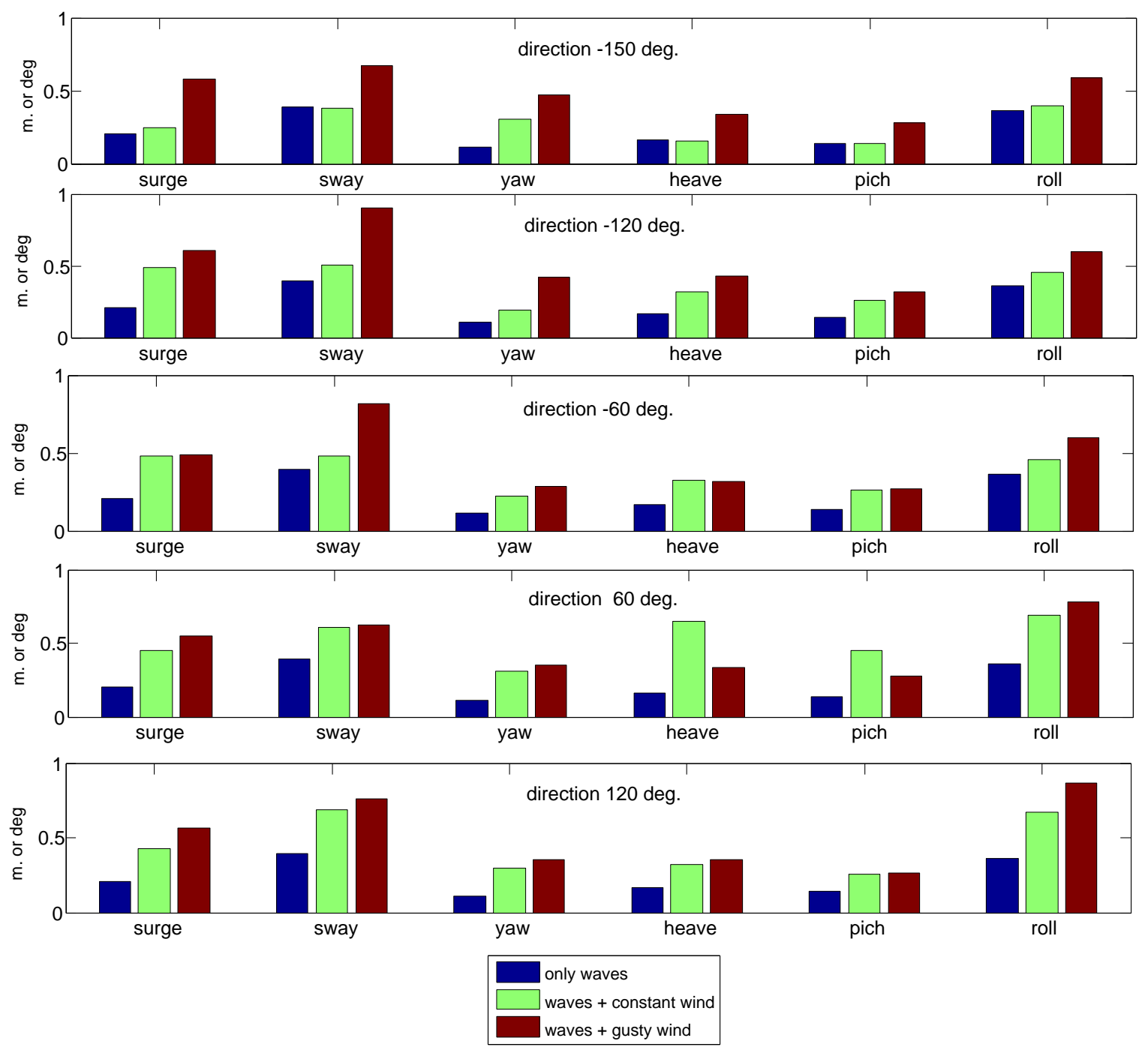

Fig. 21. Significant amplitude of ship motions with different wind situations $\left(V_{v}=15 \mathrm{~m} / \mathrm{s}\right)$.

controller, since it has a quicker response atr higher frequencies. However, in order for the system to follow the wind signal, the frequency response requirements are no more than $1.5-2 \mathrm{~Hz}$, meaning the $\mathrm{P}$ controller is acceptable for this application. In order to verify this, please refer to Fig. 20, were the wind power spectral density is shown.

The Fig. 17 shows the comparison between controllers, $P$ and PD, with three different excitation signals: step signal, sinusoidal signal with a linear increase of the frequency from 0 to $10 \mathrm{~Hz}$ and finally a random gusty wind signal. For clarity reasons, only the external envelope of the sinusoidal signals is represented in the second chart.

As previously explained and for practical reasons only the $\mathrm{P}$ controller has been used in this work. The optimal adjustment of $K_{P}$ has been experimentally calculated through trial and error methods, and independently for every gearbox and spring chosen.

\section{Experiments and results}

A set of tests with different external conditions have been carried out. These can be classified in four groups:

- Tests that only consider the action of the waves.

- Tests that only consider the action of the wind.

- Tests with the action of the waves and a gusty wind.
- Tests with the action of the waves and a constant wind.

The waves used in the tests were always identical, with the following full scale characteristics, as was explained in Section 2: $H_{S}=4.57 \mathrm{~m}, P_{P}=14.8 \mathrm{~s}$, Direction N-050-W.

The gusty wind reproduced in the tests corresponds to a full scale speed of $15 \mathrm{~m} / \mathrm{s}(15 \mathrm{~m} / \mathrm{s})$ at $10 \mathrm{~m}$ high, "blowing" from the following directions. The angles tested were:

$\pm 30^{\circ}, \pm 45^{\circ}, \pm 60^{\circ}, \pm 90^{\circ}, \pm 120^{\circ}, \pm 135^{\circ}, \pm 150^{\circ}$

In order to evaluate the wind contribution depending on the angle of incidence, the angles tested were more than those considered in the full scale situation.

In addition and, in order to validate whether or not it is important to reproduce the wind fluctuation component, some few tests using a constant wind were also performed. For this type of wind only the directions $\pm 60^{\circ}, \pm 120^{\circ}$ and $-150^{\circ}$ were tested.

The wind direction angles are measured with respect to the centreline plane, considering this as an angle 0 . The positive angle corresponds to the clockwise direction (see Fig. 18).

For each test, the variables being measured were:

- Tensions in the 6 mooring lines.

- Reactions in the 4 fenders.

- Ship motions. 
Table 3

Comparative table of ship motion increments.

\begin{tabular}{|c|c|c|c|c|}
\hline \multirow[t]{2}{*}{ Wind direction } & \multirow[t]{2}{*}{ Movement } & \multirow{2}{*}{$\begin{array}{l}\begin{array}{l}\text { Constant/ } \\
\text { waves }\end{array} \\
\%\end{array}$} & \multirow{2}{*}{$\begin{array}{l}\text { Gusty/ } \\
\text { waves }\end{array}$} & \multirow{2}{*}{$\begin{array}{l}\begin{array}{l}\text { Gusty/ } \\
\text { constant }\end{array} \\
\%\end{array}$} \\
\hline & & & & \\
\hline \multirow{4}{*}{-150} & Surge & 18.1 & 180.4 & 137.4 \\
\hline & Sway & 2.4 & 75.7 & 71.6 \\
\hline & Yaw & 176.5 & 327.9 & 54.8 \\
\hline & Roll & 8.2 & 61.7 & 49.4 \\
\hline \multirow{4}{*}{-120} & Surge & 136.0 & 192.0 & 23.7 \\
\hline & Sway & 28.3 & 130.3 & 79.5 \\
\hline & Yaw & 72.2 & 285.7 & 123.9 \\
\hline & Roll & 24.1 & 64.7 & 32.7 \\
\hline \multirow[t]{4}{*}{-60} & Surge & 134.4 & 137.0 & 1.1 \\
\hline & Sway & 23.7 & 109.0 & 69.0 \\
\hline & Yaw & 105.5 & 159.8 & 26.4 \\
\hline & Roll & 25.9 & 64.3 & 30.4 \\
\hline \multirow[t]{4}{*}{60} & Surge & 116.4 & 166.4 & 23.1 \\
\hline & Sway & 54.7 & 59.2 & 2.9 \\
\hline & Yaw & 183.3 & 217.5 & 12.1 \\
\hline & Roll & 89.6 & 115.2 & 13.5 \\
\hline \multirow[t]{4}{*}{120} & Surge & 106.5 & 175.2 & 33.3 \\
\hline & Sway & 75.1 & 94.4 & 11.1 \\
\hline & Yaw & 169.2 & 224.8 & 20.7 \\
\hline & Roll & 85.6 & 138.2 & 28.3 \\
\hline
\end{tabular}

Every ship has 6 degrees of freedom (DOF), consisting 3 linear displacements (surge, sway and heave) and 3 angular displacements (roll, pitch and yaw). Due to the actuators' layout, where the force is applied within a horizontal plane, and since the longitudinal force has been considered negligible, both motions heave and pitch have been discarded from the analysis. In Fig. 19, the four DOF which have been analysed, are clarified with their positive signs, and the final actuators' layout (the configuration shown in Fig. 13, actually represents each actuator's place).

\subsection{Results}

Several types of analysis have been carried out. Firstly, the capacity of the wind implementation system to reproduce the theoretical wind signal has been verified. Then, several combinations regarding the measured variables on the ship have been studied.

\subsubsection{Wind signal reproduced}

As previously stated, the capacity of the system is analysed in this section, i.e. the combination of motor-gearbox-controller, to reproduce or to follow the theoretical wind force signal that should be applied on the ship. The power spectral density corresponding to both bow and stern configurations are shown bellow. For each of these three signals are plotted, the theoretical wind signal and the actual scaled signals applied on the ship for two scenarios: with wind only and with the combination of both waves and wind (see Fig. 20). The wind direction chosen for this experiment was $30^{\circ}$.

According to the previous figure, it can be stated that both bow and stern motor-gearbox sets with the use of the P controller, are perfectly capable to reproduce the spectrum wind signal within the frequency range of $0-2 \mathrm{~Hz}$. It can be noted that, between 0 and $2 \mathrm{~Hz}$ the wind practically contains, the whole amount of its energy. Note also that the frequencies of the horizontal axis correspond to the scale model.

\subsubsection{Comparison of a constant wind vs gusty wind. a motions analysis}

In this section, the significant amplitude of each motion for five wind directions is analysed. For each, three scenarios were
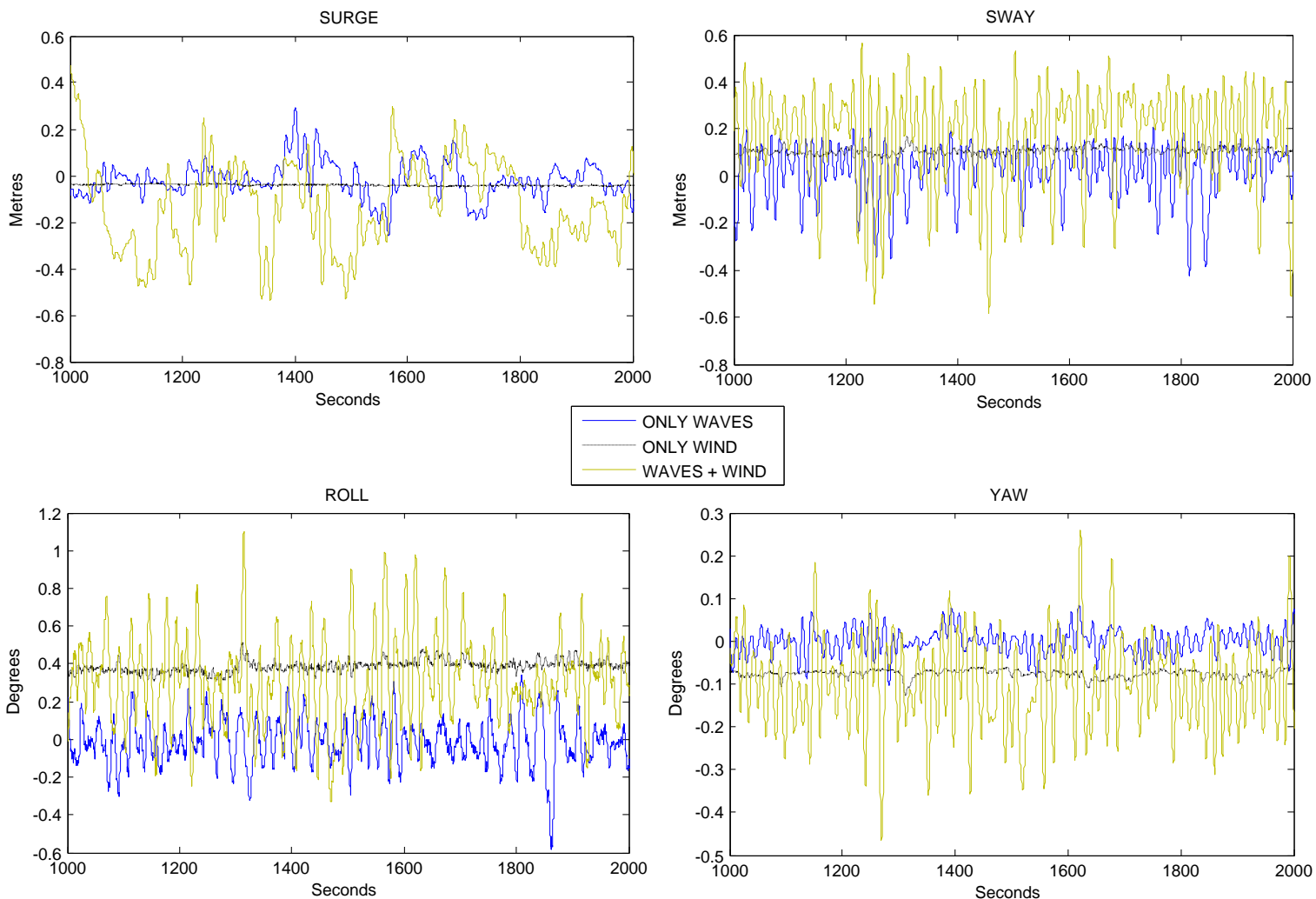

Fig. 22. Superposition effect of a $60^{\circ}$ wind on motions. 

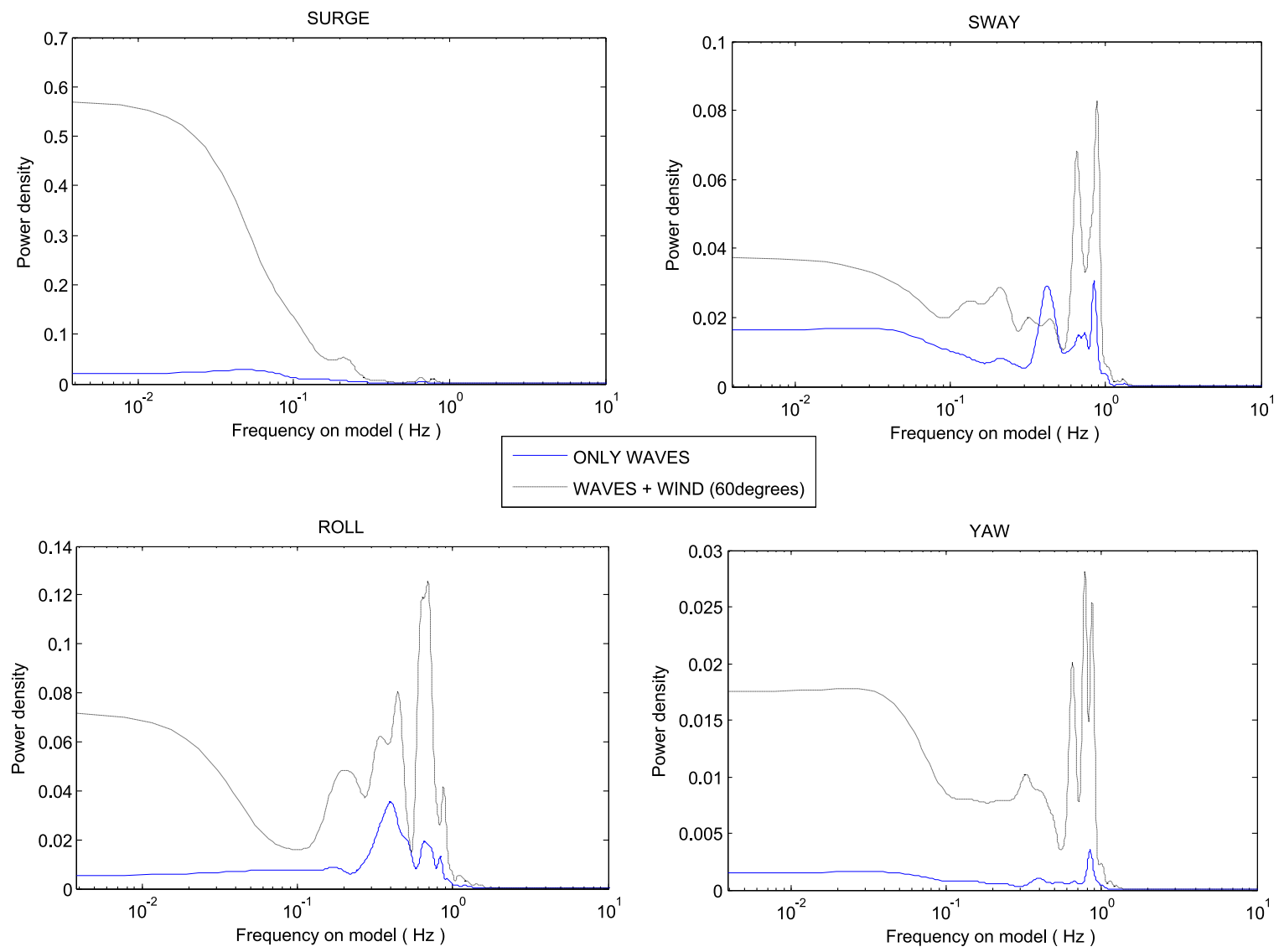

Fig. 23. Frequency spectra of motions (waves only vs waves with $60^{\circ}$ wind).

considered: 1 . only waves, 2 . waves with a constant wind and 3 . waves with a gusty wind. The significant amplitude of a variable is the average value of the upper third of the amplitudes of that variable.

The results are qualitatively shown in Fig. 21 by means of bardiagrams. The units in the vertical axis are metres for surge and sway, and degrees for yaw and roll.

The results clearly show that scenario 2 (waves with a constant wind) increases the amplitudes of the motions in comparison to the tests that only consider waves. A further increase of the amplitudes can also be seen for scenario 3 (waves with a gusty wind). In absolute terms the largest motions observed, have been for sway and roll, not exceeding one metre or one degree respectively.

Next, a quantitative comparison in percentage between the three scenarios is shown in Table 3. The first and second data columns represent the increase of significant amplitude of the motions for the scenarios 2 and 3 with respect to the scenario 1 (waves only). The last data column represents the increase of scenario 3 (waves with a gusty wind) with respect to scenario 2 (waves with a constant wind). In addition, the 10 highest and lowest variations are highlighted in green and yellow respectively.

From the first and second data columns, it can be concluded that most of the obtained motions in scenario 3 double in value those of scenario 1 . The biggest increase occurs for the yaw motion ( $327 \%$ and $285 \%$ ) for the directions $-150^{\circ}$ and $-120^{\circ}$ respectively. The smallest increase (2.4\%) belongs to the sway for the direction150 degrees.

Regarding the last data column, it can be said that most of the motions in scenario 3 are significantly greater than those present in scenario 2 . The increase with a $60^{\circ}$ wind is the smallest of all of the directions considered in this table. This may be due to the effect of wind, since it pushes the ship against the quay and hence, letting fenders absorb the energy of the wind.

According to the results obtained in the ship motions, it has been demonstrated on one hand, the importance of reproducing the wind in these kind of tests and, on the other hand, the importance of reproducing the fluctuation component to the wind (gusty wind), and not only its mean value (constant wind). This validates the idea revealed in Fig. 21.

\subsubsection{Superposition effect of the wind. motions, lines and fenders analysis}

The "superposition effect" of the wind in the analysis of motions, lines and fenders is analysed in this section. In order to qualitatively visualise this "superposition effect", time series of motions, tensions in lines and reactions in fenders are separately compared for three different scenarios: only waves, only wind and waves with wind.

In order to keep this document at a reasonable size, only the plots corresponding to the ship motions are shown (see Fig. 22). Note that these plots correspond to $\mathrm{a}+60^{\circ}$ wind. All of the units are referred to the real scale.

According to Fig. 22, it can be stated that there really is a clear superposition of effects. The same conclusion is also obtained when numerical modelling techniques are used (Zaheer and Islam, 2012). For the scenario "waves with wind" every motion becomes greater than for the scenario "waves only", in terms of both peak values and travel (difference between maximum and minimum consecutive values). Also, the mean value of each motion moves from nearly zero, in the "waves only" scenario, to the mean value that it presents in the "wind only" scenario.

The line tension and fender force analysis shows a similar behaviour, with some singularities. In particular, the $60^{\circ}$ wind causes an effect such that the ship is pushed harder against the fenders 


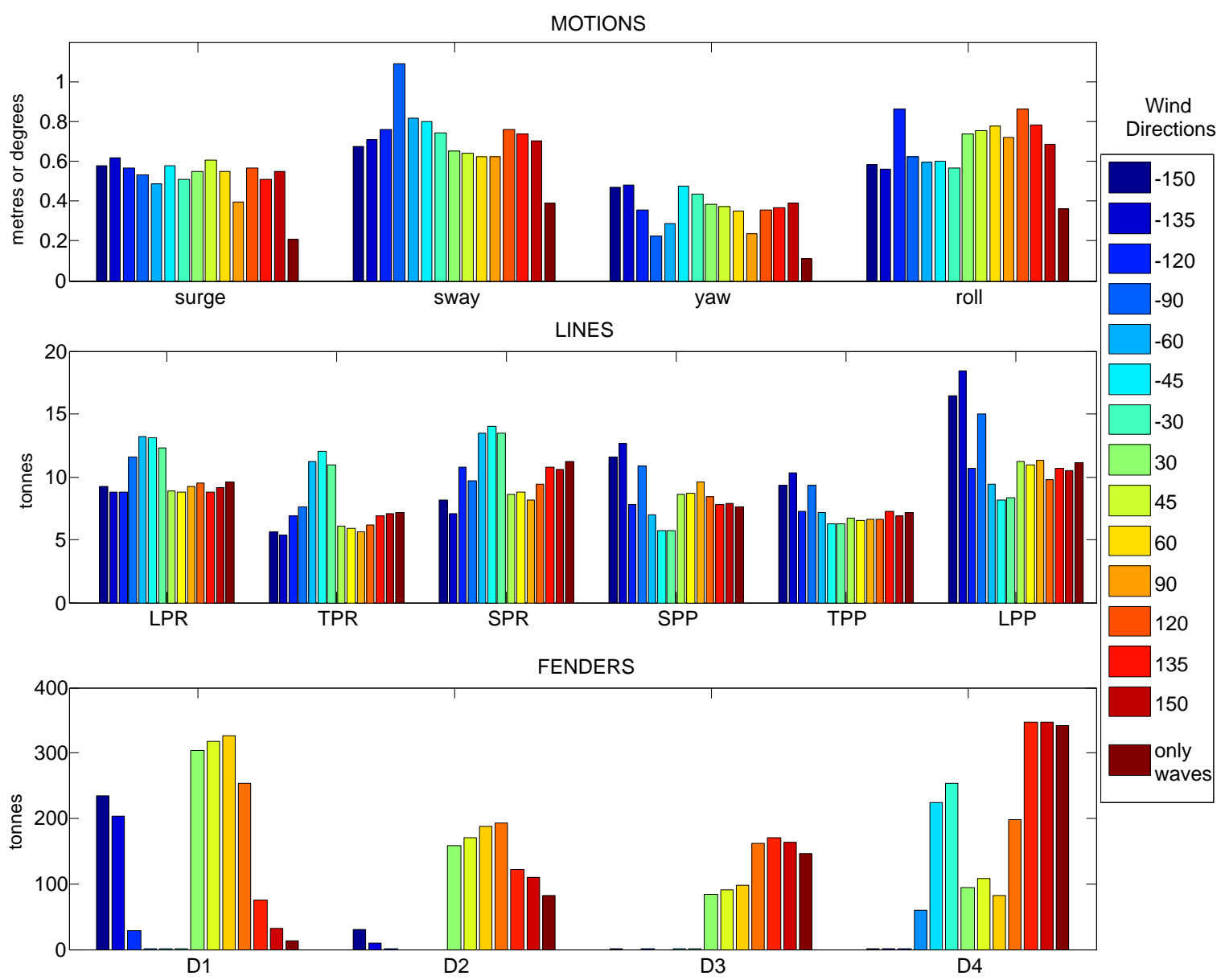

Fig. 24. Significant amplitudes of motions and efforts. $V_{v}=15 \mathrm{~m} / \mathrm{s}$ gusty wind and waves.

located fore, whereas the ones located aft are almost "released" from tension.

The effect of different wind directions is discussed in a later section.

\subsubsection{Superposition effect of the wind. motion spectral analysis}

Within the motion analysis, it is also interesting to observe the superposition effect of the wind by means of the power spectral density. In the following, a comparison of each individual ship motion for two different scenarios is presented. As for the previous section, the two scenarios being studied are "waves only" and "waves with a $60^{\circ}$ wind". This will give a clearer view on how the wind alters the ship motions (Fig. 23).

The results observed confirm that the wind amplifies the energy of every motion while keeping the same main frequencies. It can also be noted that an important amount of energy is present in the low and very low frequency region, which did not appear in the "waves only" scenario. This additional energy due to the wind contribution can easily be explained since wind contains a significant amount of energy in that frequency range (see Fig. 20). Similar results were found by Zaheer and Islam (2012) through numerical modelling.

\subsubsection{Effect of different wind directions. motions, lines and fenders analysis}

In order to study how the different wind directions affect the behaviour of the ship, the Fig. 24 is presented. In it, a comparison of the significant amplitudes of motions, efforts in lines and reactions in fenders, is made for each wind direction. The graphs are in the way of bar plots, where each bar represents a different wind direction. The "waves only" scenario is also included in the last bar of each group, labelled as "only waves".

The gusty wind directions being tested were: $-150,-135$, $-120,-90,-60,-45,-30,30,45,60,90,120,135,150^{\circ}$, with a wind speed of $15 \mathrm{~m} / \mathrm{s}$ (see the beginning of Section 5 ).

The vertical axis of every plot is in metres for surge and sway, in degrees for roll and yaw, and in tonnes for the forces in lines and fenders. The legend pertaining to lines (as described in Section 2) on the horizontal axis is as follows: stern lines (LPP), breast lines aft (TPP), springs lines aft (SPP), spring lines bow (SPR), breast lines bow (TPR) and head lines (LPR). In the case of fenders, D1 is the first fender in contact with the hull fore and D4 the last fender in contact with the hull aft of the ship.

\subsection{Motions analysis}

A big increase is observed when wind and waves act together. The lowest value of every motion is always the last column (which only considers the action of the waves).

If the different wind directions are analysed, it appears that the surge experiences no significant variations as the wind angle changes. The sway acquires its greatest value for a $-90^{\circ}$ wind. This result seems logical since this wind direction acts perpendicular to the ship and tends to move it away from the dock. The lowest sway value is obtained with $+90^{\circ}$ (wind acting on the starboard side), where the vessel is pushed against the dock and the fenders restrict its motion. The yaw has the lowest values for $-90^{\circ}$ and $+90^{\circ}$ directions, which once again, seems logical. 

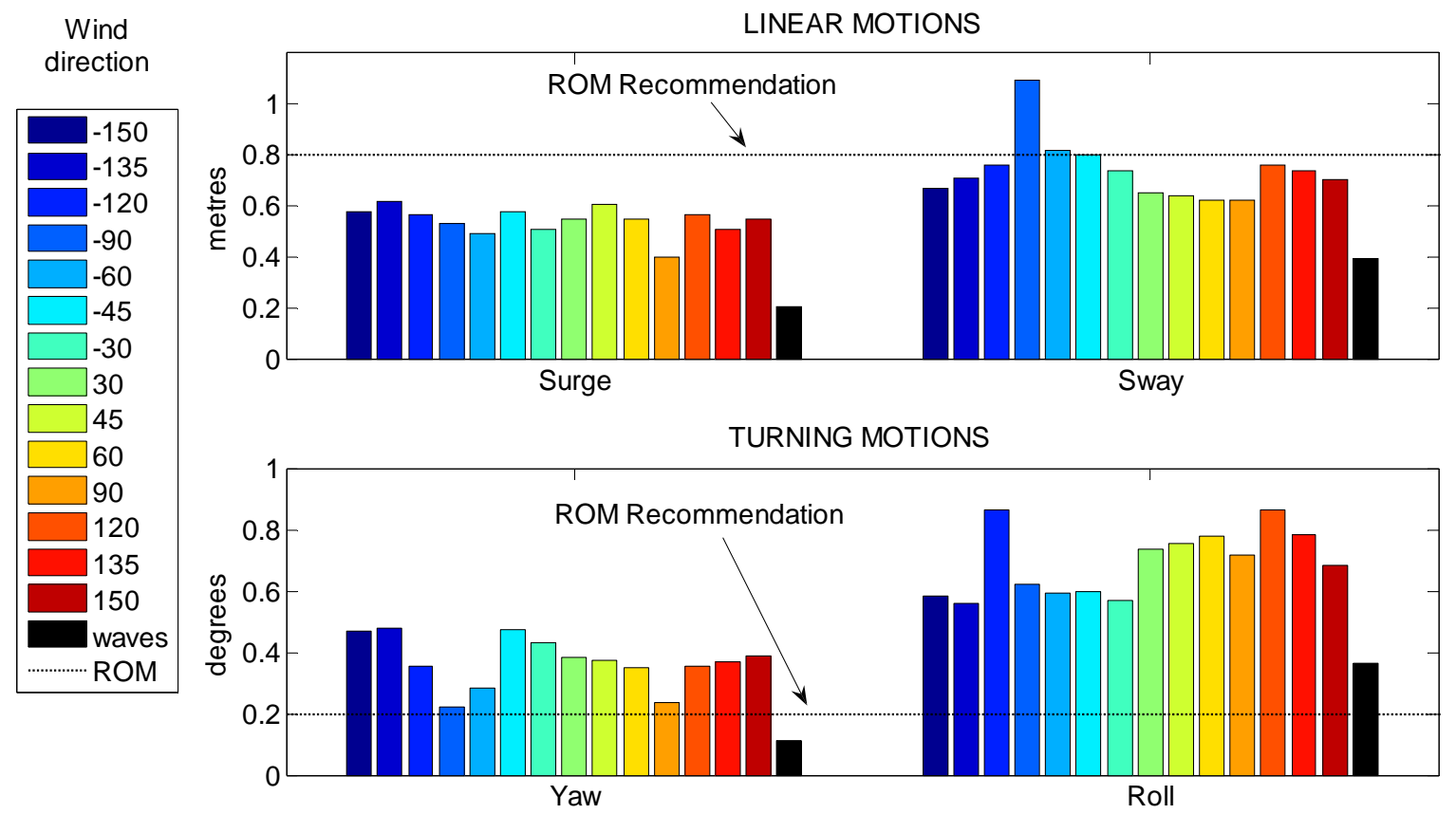

Fig. 25. Significant amplitudes and ROM recommendations. $V_{v}=15 \mathrm{~m} / \mathrm{s}$ gusty wind and waves.

\subsection{Lines analysis}

The significant amplitude of the effort in the lines increases or decreases, in relation to the "waves only" scenario, depending on the wind direction and how this tends to move the ship. For example, in the case of a $-90^{\circ}$ wind, the ship is moved away from the dock, increasing the tension in every line. In the cases where the wind makes the ship yaw, some lines support more effort while others support less.

Nevertheless, the obtained results are of a similar order of magnitude than those obtained in the "waves only" scenario. The greatest efforts are achieved in the stern line (LPP) between $-150^{\circ}$ and $-90^{\circ}$ winds.

\subsection{Fenders analysis}

In general, fenders support more load with positive wind directions, (where the ship is pushed against the dock) and the opposite occurs with negative wind directions (where the ship is moved away from the dock). The greatest values are always obtained either in fender 1 or 4 , depending on the wind case. These values are greater, in fender 1 with wind blowing fore $(30,45$ and $\left.60^{\circ}\right)$ and in fender 4 with wind blowing aft $\left(120,135\right.$ and $\left.150^{\circ}\right)$.

\section{Discussions and conclusions}

After the tests carried out in this study, the main conclusions can be highlighted in the following points.

- The proposed system which implements the wind effect on moored ships, composed of double-spring closed circuit, rotatory actuator and proportional controller, offers some good results according to the power spectral plots when the theoretical wind force and the applied wind force are compared. Both, the gear box and controller gain must be chosen for each particular wind direction and for each application point (bow or stern).

- Both, tests including a constant wind and gusty wind, have significantly increased motions amplitudes, compared with the "waves only" scenario.

- If the same wind speed is reproduced, the gusty wind causes greater motions in the ship than the constant wind. This confirms that the "fluctuation" component of the wind or gust effect must be taken into account in this kind of tests.

- Qualitatively, a superposition of effects in the time series of the ship motions is observed when the three scenarios "waves only", "wind only" and "waves with wind" are compared.

- The spectral analysis of the ship motions with and without wind reveals that the wind amplifies the power of every considered ship motion across the whole frequency range. The frequency peaks associated to the ship motions remain in the same position.

- The wind direction affects the motions, ropes and fenders in different way.

- The amplitude of the ship motions is strongly increased. If these amplitude values, achieved in the tests including wind, are compared to the maximum recommendable values from the Spanish Standard ROM 2.0-11 (2011) (see Fig. 25), the cruise ship would

- have difficulties in the loading and unloading operations with some wind directions and the considered speed $(15 \mathrm{~m} / \mathrm{s})$. In particular, the vessel would exceed the threshold values for yaw and roll motions with all the wind directions tested, while in the case of sway, the threshold would only be exceeded with a $-90^{\circ}$ wind. Again the last bar, labelled as "waves", reflects the "waves only" scenario. The threshold value is shown by a dashed line.

Regarding the lines and fenders, the efforts become significantly greater or smaller depending on the wind direction. In the case of some negative wind directions, some or even all fenders may be under the influence of no tension at all. According to the maximum values obtained in these tests, no lines would exceed the maximum work load, whereas some fenders might exceed theirs.

As a final conclusion, it must be highlighted that in case of ships with considerable superstructure, such as cruises or container ships, the action of the wind should be taken into account in moored ship tests in order to achieve safer and more realistic results representing the real-scale behaviour. 
Bec, J., 2010. Influence of Wind Spectrum Formula Choice on Footbridge Response. Lublin University of Technology, Poland.

Blendermann, W., 1993. Wind loads on moored and maneuvering vessels. In: Proceedings of the12th International Conference on Offshore Mech. and Artic Engng., NY: ASME, 1993, v1, p. 183.

Chakrabarti, S.K., 1998. Physical model testing of floating offshore structures. Dynamic Positioning Conference. (October 13-14).

Chen, C.T., 1993. Analog and Digital Control system Design: Transfer-function, State-space and Algebraic Methods. Oxford University Press.

Fujiwara, T., Ueno, M., Ikeda, Y., 2006. Cruising performance of a large passenger ship in heavy sea. In: Proceedings of the 16th Int, Offshore and Polar Engng. Conference.

Gomez Pina, G., Iribarren Alonso, R., 1993. Análisis crítico de los sistemas de atraque de buques. CEDEX. Centre for Studies and Experimentation on Public Works, Spain.

Haddara, M.R., Guedes Soares, C., 1999. Wind loads on marine structures. Mar. Struct. 12, 199-209.

Hughes, S.A., 1993. Physical models and laboratory techniques in coastal engineering. Adv. Ser. Ocean Eng. 7.

Natarajan, R., Ganapathy, C., 1995. Model experiments on moored ships. Ocean Engineering 24 (7), 665-676 1997.

ROM 0.4-95, 1995. Maritime works recommendations. On climate actions in the project II. Wind,Ministry of Transport of Spain.

ROM 2.0-11, 2011. Recomendaciones de obras marítimas. Recomendaciones para el proyecto y ejecución en Obras de Atraque y Amarre.

Tursini, L., 1953. Leonardo da Vinci and the problems of navigation and naval design. Trans. Inst. Nav. Arch. 95, 97-102.

Xian-Ying, S., et al., 2014. Experimental study of characteristics of motions of a large mooring ship in long-period waves. J. Mar. Sci. Technol. 22, 240-246 (2014).

Zaheer, M.M., Islam, N., 2012. Stochastic response of a double hinged articulated leg platform under wind and waves. J. Wind. Eng. Ind. Aerodyn. 111, 53-60.

\section{Further reading (websites were opened on September 11, 2015)}

〈http://www.amc.edu.au/maritime-engineering/model-test-basin〉.

〈www.deltares.nl〉.

Chakrabarti, 1998. Physical Model testing of floating offshore structures. Dynamic
Positioning Conference. Houston.

〈http://www.nrc-cnrc.gc.ca/eng/solutions/facilities/marine_performance/engineer ing_basin.html $\rangle$.

〈http://www.nrc-cnrc.gc.ca/eng/solutions/facilities/marine_performance/towing tank.html $\rangle$.

〈http://moeri.kordi.re.kr/kordi_daeduck/data/file/kordi_8p.pdf〉.

〈http://oe.sjtu.edu.cn/eng.php/Eng/article_gallery/listPage/parentID/1619/cat_id/ $1637\rangle$.

〈http://oe.sjtu.edu.cn/eng.php/Eng/article_gallery/listPage/parentID/1619/cat_id/ $1633\rangle$.

Physical Model Experiments on floating off shore wind turbines. In: Proceedings of the HYDRALAB IV Joint User Meeting, Lisbon. July 2014.

〈http://www.ihcantabria.com/es/ihlab-menu/ihlab-hidro/item/697〉.

$\langle$ http://www.cehipar.es/instalaciones/dinamicabuque/〉.

Weiler, O., et al., 2009. Motinons and mooring loads of an LNG-carrier moored at a jetty in a complex bathymetry. OMAE2009-79420.

〈http://www.insean.cnr.it/sites/default/files/ITTC-CoF-2.pdf).

〈http://www.nmri.go.jp/english/research_facilities.html〉.

$\langle$ http://www.sintef.no/en/marintek/laboratories/〉.

$\langle$ http://www.krylov-center.ru/eng/experimental_facilities/basin-sea/〉.

〈http://otrc.tamu.edu/pages/basinspecs.htm〉.

Murray, J., et al., 2008. An Extended Tension Leg platform Design for Post-Katrina Gulf of Mexico. Texas, Houston.

〈http://www.marin.nl/web/Facilities-Tools/Basins/Offshore-Basin.htm〉.

Nagata, et al., 1999. Motions of a movable floating bridge in waves. In: Proc. VLFS'99. Honolulu.

〈http://www.marin.nl/web/Publications/Publication-items/Complex-model-testson-MOHO-NORD-Tension-Leg-Platform.htm $\rangle$.

〈http://www.laboceano.coppe.ufrj.br/en/laboceano/laboceano.php〉.

Zamora-Rodriguez, R., et al., 2014. Model Scale Analysis of a Tlp Floating Offshore Wind Turbine. Offshore and Arctic Engineering, OMAE (2014).

Thiagarajan, K., et al., 2015. Measurement and modeling of wind directionality for better design and operation of floating offshore wind turbines. PO.ID.92. EWEA Offshore 2015 - Copenhagen - 10-12 March, 2015.

〈https://scripps.ucsd.edu/hlab/facilities〉. 